\title{
KOMPETENSI MINIMAL PROFESI SEKRETARIS DIREKSI DI SEPULUH PERUSAHAAN INDONESIA
}

\author{
Selfiana \\ Program Studi Sekretari, Akademi Sekretari dan Manajemen Bina Insani, Indonesia \\ selfianas@gmail.com
}

\begin{abstract}
Abstrak: Kompetensi Minimal Profesi Sekretaris Direksi di Sepuluh Perusahaan Indonesia. Tujuan penelitian ini adalah untuk melakukan pemetaan terhadap kompetensi minimal yang harus dimiliki oleh seorang sekretaris direksi agar memiiki kemampuan yang tinggi guna penyelesaian tugas dan tanggungjawabnya dengan baik. Diharapkan juga agar penelitian ini dapat menjadi rujukan bagi calon sekretaris direksi dalam mempersiapkan dengan tepat dalam membangun kompetensi yang sesuai dengan kebutuhan profesi tersebut. Penelitian ini menggunakan pendekatan deskriptif kualitatif. Hasil penelitian menunjukkan bahwa kompetensi utama yang harus dimiliki sekretaris direksi adalah pribadi yang dapat dipercaya, memiliki perhatian pada pekerjaannya, memiliki pengetahuan berbahasa asing, memiliki keahlian menggunakan bahasa Indonesia dan bahasa asing, memiliki ketrampilan berkomunikasi serta memiliki pengalaman kerja di bidang perkantoran dan tata usaha kantor.
\end{abstract}

Kata kunci: Kompetensi, Sekretaris.

\begin{abstract}
Minimum Competence Secretary of Director in Ten Indonesian Companies. The purpose of this study is to map the minimum competencies that must be owned by a director's secretary so that they have a high ability to properly complete their duties and responsibilities. It is also hoped that this research can be a reference for prospective secretaries of directors in preparing properly in developing competencies that are in accordance with the needs of the profession. This research use desciptive qualitative approach. The results showed that the main competencies that the directors' secretaries must possess are individuals who can be trusted, have attention to their work, have foreign language knowledge, have expertise in using Indonesian and foreign languages, have communication skills and have work experience in office and office administration.
\end{abstract}

Keyword: Competence, Secretary.

\section{PENDAHULUAN}

Sekretaris direksi memiliki tugas dan tanggungjawab yang besar dan beragam dalam membantu pimpinan eksekutif mencapai kinerja optimal saat menjalankan bisnis perusahaan. Guna mencapai tujuan tersebut, sekretaris direksi harus kompeten di bidangnya dan memiliki ketrampilan kesekretariatan yang tinggi di atas rata-rata. Mereka diharuskan memiliki kemampuan dalam menangani aneka tugas menantang disertai tingkat kesulitan yang tinggi yang dibebankan oleh atasan sehingga profesionalitas yang disertai kompetensi dalam penyelesaian tugas-tugas menjadi sesuatu yang niscaya. Perusahaan dengan banyak sekretaris profesional yang mumpuni akan dapat menjalankan roda administrasi perusahaan secara efektif dan efisien sehingga mendukung upaya perusahaan dalam mencapai kesuksesan. Kompetensi yang dimiliki tidak terbatas hanya menyangkut pada pekerjaan administrasi perkantoran saja, tetapi juga perlu dilengkapi dengan 
kompetensi tambahan di luar kompetensi utamanya mengingat tugas dan tanggung jawabnya dalam mendukung aktivitas atasan yang luas, beragam dan kompleks. Kompetensi faktual yang dimiliki perlu diidentifikasi dan dipahami guna melakukan perencanaan dalam pengembangan kompetensi yang berkelanjutan agar dapat terus mengimbangi tugas-tugas dengan tingkat kesulitan yang semakin menantang.

Permasalahannya adalah, perusahaan maupun sekretaris direksi belum dapat mengenali dan melakukan pemetaan kompetensi utama dan pendukung secara akurat sesuai kebutuhan guna mendukung terselesaikannya tugas-tugas penuh tantangan di era digital ini. Mengidentifikasi hal ini merupakan perihal yang krusial. Adanya kesenjangan antara yang dibutuhkan perusahaan dan kompetensi riil para sekretaris akan berakibat pada tidak terselesaikannya tugas secara sempurna, meleset dari ekspektasi yang berakibat pada tidak terpenuhi target-target, tidak sesuai dengan harapan semula. Penting sekali melakukan pemetaan kebutuhan kompetensi minimal yang harus dimiliki sekretaris bahkan sejak proses seleksi dan rekrutmen.

Penelitian ini dilakukan untuk melakukan pemetaan kompetensi sekretaris direksi agar didapat daftar minimal kompetensi-kompetensi inti yang harus dimiliki serta menjadikannya sebagai rujukan pengembangan diri agar dapat menyelesaian tugas dan tanggungjawab sebagai seorang sekretaris direktur dengan dukungan kompetensi yang mumpuni.

Berdasarkan penelitian Kristiana dan Selfiana berjudul kompetensi dan kebutuhan sekretaris dan administrasi profesional terkini di sepuluh perusahaan Indonesia, seorang sekretaris harus memiliki kepribadian yang menarik, handal dibidang komunikasi dan menggunakan teknologi informasi perkantoran. Kompetensi lain yang harus di miliki adalah kemampuan berpikir kritis, kreatif dan inovatif [Widiawati and Selfiana, 2018]. Penelitian Selfiana berjudul kompetensi sekretaris terkini mengatasi era revolusi industri 4.0 di sepuluh Badan Usaha Milik Negara Indonesia menunjukkan bahwa seorang sekretaris harus memiliki kemampuan berkomunikasi, memiliki kemampuan beradaptasi yang tinggi dan sikap positif. Selain itu sekretaris juga harus memiliki penampilan yang menarik, dan memiliki motivasi tinggi dalam bekerja. Namun kompetensi bidang teknologi tidak menjadi persyaratan utama yang wajib dimiliki oleh para sekretaris di BUMN [Selfiana, 2018].

Seorang sekretaris didefinisikan sebagai asisten eksekutif yang memiliki penguasaan keahlian dalam perkantoran; orang yang menunjukkan kemampuan untuk memikul tanggungjawab tanpa pengawasan langsung; orang yang menjalankan inisiatf dan keputusan; dan orang yang membuat keputusan dalam lingkup kekuasaan yang ditugaskan [Gaol, 2015].

Untuk menjadi seorang sekretaris yang berkompeten harus memenuhi persyaratan berikut : 1 . Syarat kepribadian: mampu bersikap mawas diri, ramah, sabar, simpatik, penampilan diri yang 
baik, pandai bergaul, dapat dipercaya, bersikap bijaksana terhadap orang lain, memiliki ingatan baik, mempunyai perhatian atas pekerjaannya. 2. Syarat pengetahuan: memiliki pengetahuan kemasyarakatan kebudayaan yang akan mengangkat nama perusahaan yaitu menguasai bahasa Indonesia dan beberapa bahasa asing secara lisan dan tertulis, memiliki pengetahuan ekstra dan pengetahuan tentang misi, fungsi, tugas-tugas serta struktur organisasi dan susunan personel. 3 . Pengetahuan tentang korespondensi, tata kearsipan. 4. Pengetahuan khusus: sekretaris memiki pengetahuan mengenai hal-hal yang berkaitan dengan hal-hal yang berhubungan dengan dunia bisnis tempatnya bekerja. 4. Syarat keahlian: sekretaris memiliki ketrampilan untuk menunjang pekerjaannya yaitu kemampuan menyusun laporan, berkorespondensi, menggunakan bahasa Indonesia dan bahasa asing, teknik menyimpan arsip, teknik berkomunikasi menggunakan telepon, menulis cepat dengan steno dan teknik mengetik surat. 5. Syarat praktik : seorang sekretaris memiliki pengalaman dalam berbagai pekerjaan di bidang perkantoran dan tata usaha kantor [Gaol, 2015].

Kompetensi adalah kemampuan seseorang dalam menghasilkan suatu produk pada tingkat yang memuaskan di tempat kerja termasuk diantaranya kemampuan seseorang untuk mentransfer dan mengaplikasikan keterampilan dan pengetahuan tersebut dalam situasi yang baru guna memperoleh peningkatan manfaat seperti yang disepakati. Kompetensi juga menunjukkan karakteristik pengetahuan dan keterampilan yang dimiliki atau dibutuhkan oleh setiap individu yang memampukan mereka untuk melakukan tugas dan tanggungjawab mereka secara efektif dan meningkatkan standar kualitas profesional dalam pekerjaan mereka [Wibowo, 2010].

\section{METODE}

Penelitian ini merupakan penelitian deskriptif kualitatif. Metode penelitian yang dilakukan adalah metode analisa sekunder yaitu menggunakan data sekunder yang berasal dari iklan lowongan pekerjaan untuk posisi sekretaris direksi tahun 2019. Jumlah lowongan yang menjadi data penelitian berjumlah sepuluh perusahaan. Analisa data dilakukan dengan melakukan pemetaan kebutuhan kompetensi dalam upaya menyelesaikan tugas dan kewajiban seorang sekretaris direksi.

\section{HASIL DAN PEMBAHASAN}

Penelitian ini berfokus pada kompetensi yang dibutuhkan oleh seorang sekretaris direktur. Data diperoleh dari laman iklan lowongan pekerjaan indeed, joble dan jobstreet. 


\section{Sekretaris Direksi, PT Sapta Sarana Sejahtera (SSS) - Bogor.}

PT Sapta Sarana Sejahtera bergerak di bidang pertambangan. Tugas dan tanggungjawab sekretaris direksi adalah memfilter informasi dan sebagai sumber informasi bagi pimpinan dan menjalankan tugas, fungsi dan tanggungjawabnya, mengatur aktivitas perusahaan, mulai dari administrasi hingga human relations (HR), menjadi perantara pihak-pihak yang ingin berhubungan dengan pimpinan, menjadi mediator pimpinan dengan bawahan, memberikan ideide sebagai alternatif pemikiran pimpinan, pemegang rahasia penting pimpinan yang berkaitan dengan perusahaan.

Kualifikasi yang di harus dipenuhi adalah pendidikan D3 Sekretaris, IPK Diatas 3.00, penampilan menarik, pandai berkomunikasi dan cepat beradaptasi dengan lingkungan area pertambangan, menguasai micrososft Office (terutama Hlookup dan Vlookup)

Tabel 1. Kebutuhan Kompetensi PT SSS

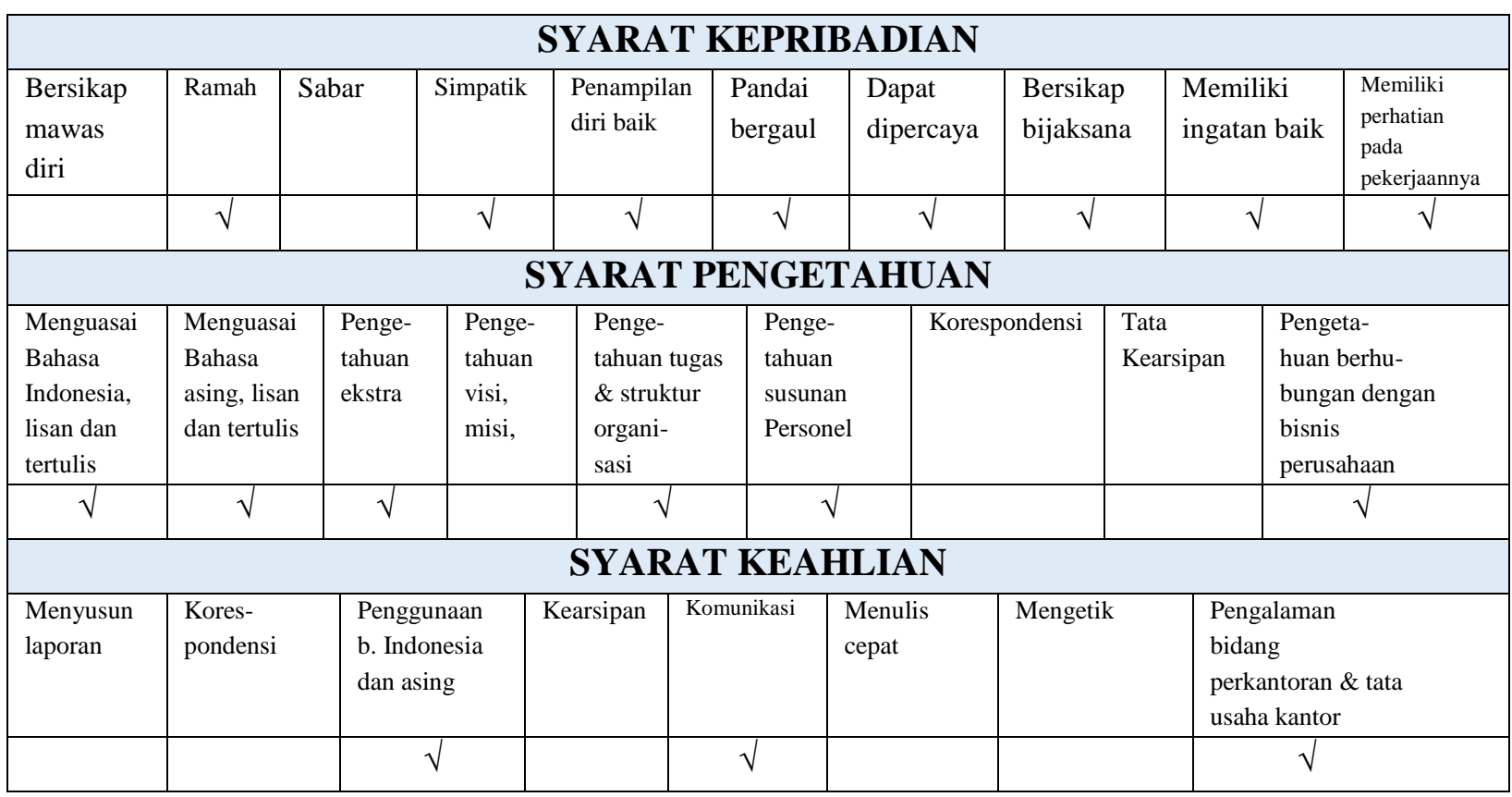

\section{Asisten Direktur, PT Wiratama Kreasi Komputindo (WKK) - Jakarta.}

PT Wiratama Kreasi Komputindo adalah perusahaan yang bergerak di bidang distribusi aksesoris handphone dan komputer. Pemilik dari brand VYATTA \& WKK. Tugas dan tanggungjawab asisten direktur adalah menginformasikan kebijakan direksi kepada pihak internal dan eksternal perusahaan, menyiapkan bahan-bahan laporan untuk rapat Direksi bersama dengan jajaran peserta rapat, mengupayakan kelancaran pelaksanaan agenda kegiatan direksi, melakukan himbauan kepada para manager maupun supervisor yang harus memberikan laporan setiap harinya kepada Direksi, menjadi notulen rapat maupun perwakilan meeting, memeriksa maupun melakukan evaluasi terhadap hasil kerja dan laporan para staff dan karyawan kepada pimpinan perusahaan. 
Kualifikasi yang di harus dipenuhi adalah minimal pendidikan S1, bisa mengoperasikan Ms. Office dan internet dengan baik, mengetik dengan cepat, memiliki jiwa kepemimpinan yang baik, mampu memberikan motivasi, arahan, dan evaluasi kepada tim nya, memiliki kemampuan memeriksa laporan yang mendetail dengan sangat teliti, memiliki pengalaman sebagai administrasi/sekretaris direksi.

Tabel 2. Kebutuhan Kompetensi PT WKK

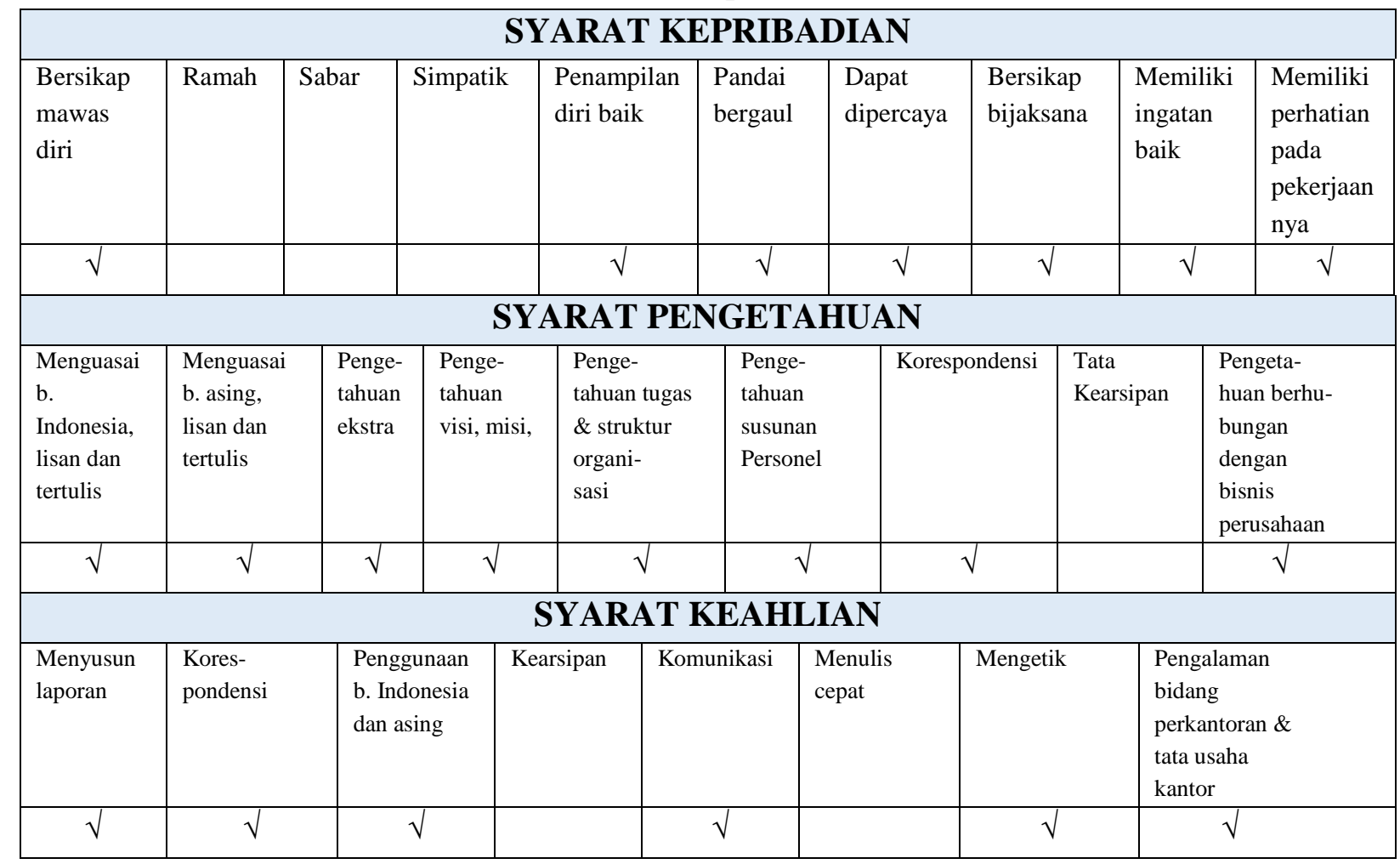

\section{Sekretaris Direktur, PT Kalibesar Raya Utama (KRU) - Jakarta}

PT Kalibesar Raya Utama adalah perusahaan pialang dan konsultan asuransi. Tugas dan tanggungjawab sekretaris direktur adalah mampu bersikap tegas dan cepat dalam mengambil keputusan, melakukan aktivitas kesekretariatan perusahaan, menyusun, menyiapkan, dan mengupayakan kelancaran pelaksanaan agenda kegiatan direksi, mengurus segala administrasi terkait kegiatan direksi, membuat dan mengelola file/dokumen perusahaan, mengorganisir pertemuan bisnis. Kualifikasi yang harus dipenuhi adalah pendidikan min. D3 jurusan kesekretarisan/administrasi, berpengalaman minimal satu tahun di bidang sekretaris, memahami dan mampu mengoperasikan microsoft office, bertanggung jawab. 
Tabel 3. Kebutuhan Kompetensi PT KRU

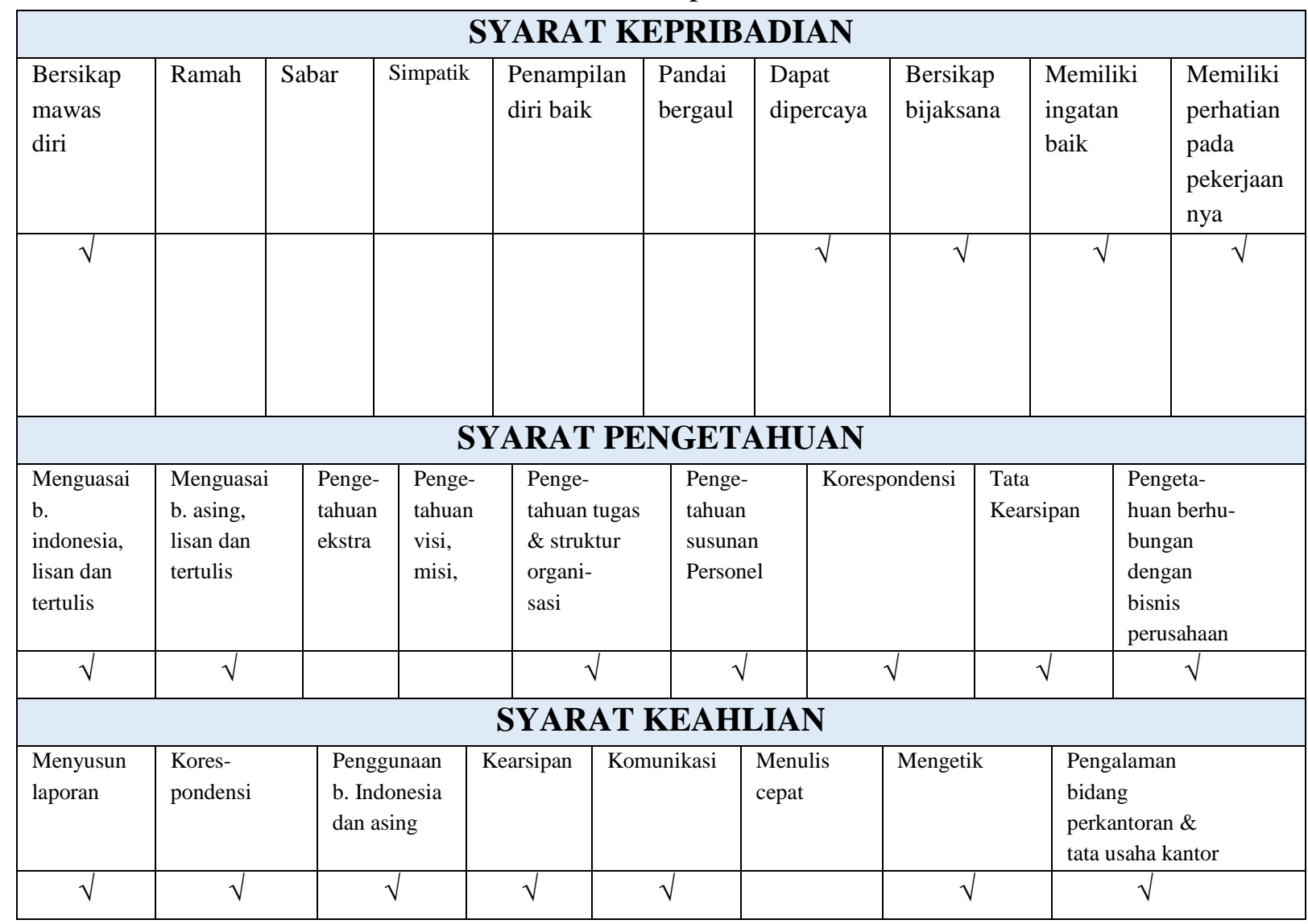

\section{Sekretaris Direksi, PT Kreasi Sukses Indoprima (KSI) - Jakarta.}

PT Kreasi Sukses Indoprima adalah perusahaan yang bergerak di bidang alat-alat pendukung industri, seperti penyedia alat-alat ukur, pompa, filter dan systems. Tugas dan tanggungjawab sekretaris direktur adalah melaksanakan tugas-tugas administrasi kesekretariatan, terutama yang bersifat kompleks dan rahasia. melakukan tugas - tugas kesekretariatan untuk mendukung tugas atau pekerjaan sehari -hari direktur, melengkapi dokumen kebutuhan import dan memprosesnya.

Kualifikasi yang harus dipenuhi adalah pendidikan minimum D3 Sekretaris, pengalaman sebagai sekretaris minimum 3 tahun dan diutamakan pengalaman sebagai sekretaris direksi/eksekutif, memiliki kemampuan bahasa inggris, dibuktikan dengan sertifikat TOEFL 450 atau IELTS 6.0, memiliki keterampilan mengoperasikan microsoft office, memiliki pengetahuan dalam proses import, memiliki ketrampilan komunikasi interpersonal dan korespondensi menggunakan bahasa inggris, mampu berbahasa mandarin, teliti dan cekatan dalam kerja serta memiliki time management yang baik. 
Tabel 4. Kebutuhan Kompetensi PT KSI

\begin{tabular}{|l|l|l|l|l|l|l|l|l|l|}
\hline \multicolumn{2}{|c|}{ SYARAT KEPRIBADIAN } \\
\hline $\begin{array}{l}\text { Bersikap } \\
\text { diri }\end{array}$
\end{tabular}

\section{Sekretaris Direktur, PT Ihaka Saka Nusantara (ISN) - Jakarta}

PT Ihaka Saka Nusantara perusahaan yang menjadi agen utama Haushahn Elevator. Tugas dan tanggungjawab sekretaris direktur adalah mengelola database inventaris dan menyimpan dokumen asli perusahaan, membuat kontrak; surat perjanjian; dokumen perbankan dan dokumen-dokumen penting lainnya yang dibutuhkan oleh pimpinan, melakukan tugas-tugas lainnya yang dibutuhkan oleh perusahaan, pemegang informasi penting pimpinan yang berkaitan dengan perusahaan, menyiapkan dokumen-dokumen yang diperlukan secara benar dan tepat waktu, mengkomunikasikan kebijakan perusahaan dengan baik kepada pihak internal maupun eksternal perusahaan.

Kualifikasi yang harus dipenuhi adalah menguasai microsoft office, mampu membuat surat penawaran dan membaca kontrak, pengalaman minimal tiga tahun di bidangnya. 
Tabel 5. Kebutuhan Kompetensi PT ISN

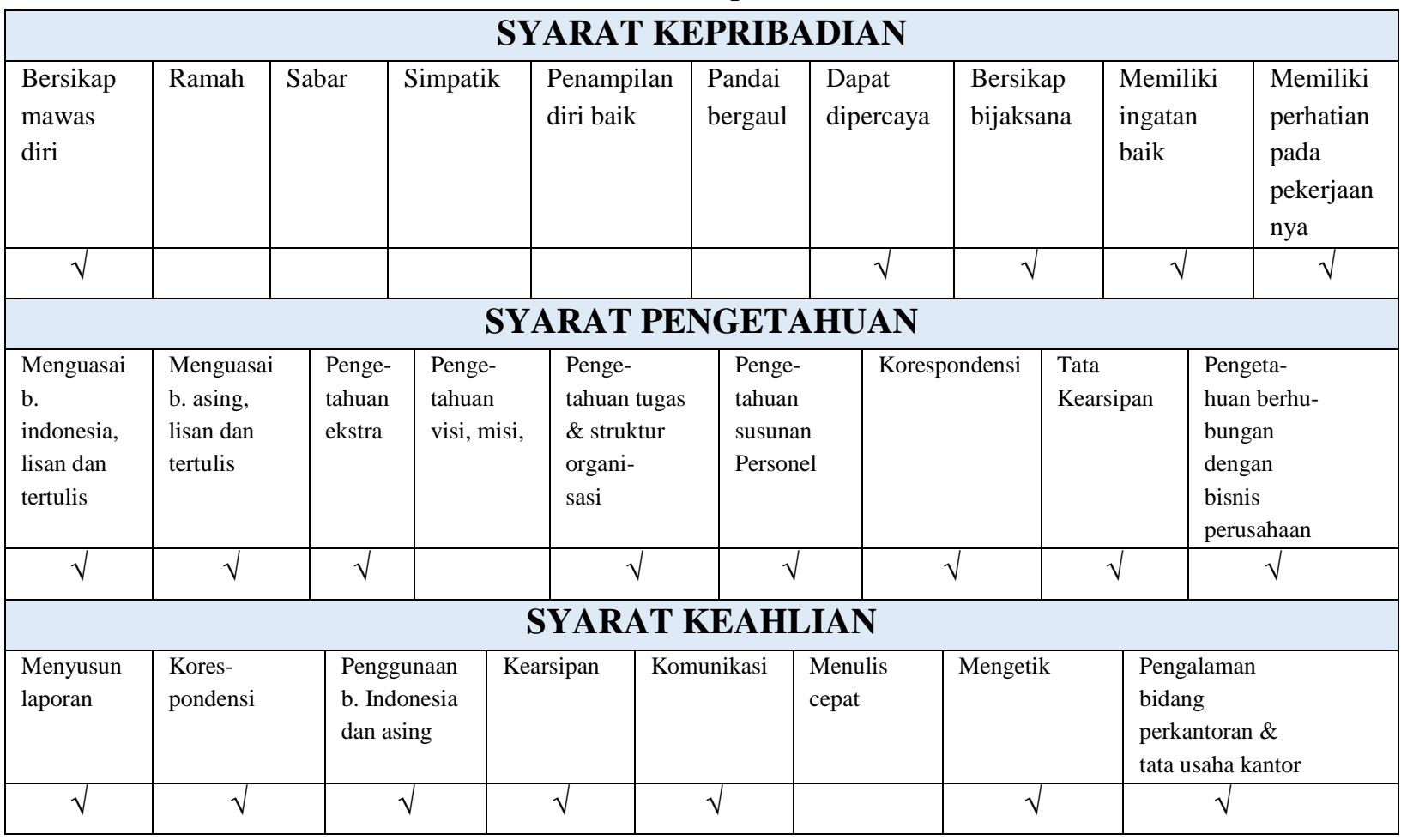

\section{Sekretaris Direksi, PT Magnesium Gosari Internasional (MGI) - Gresik}

PT Magnesium Gosari Internasional adalah perusahaan multinasional dibidang manufaktur pupuk. Tugas dan tanggungjawab sekretaris direksi adalah menyiapkan, mengatur, memonitor dan mengontrol jadwal meeting direksi; menyiapkan, melakukan kegiatan administrasi, mengatur, memonitor dan mengontrol jadwal perjalanan dan juga persiapan yang dibutuhkan dalam perjalanan dinas direksi; melakukan kegiatan administrasi, mengatur, memonitor dan mengontrol seluruh data-data administrasi yang berhubungan dengan direksi seperti surat menyurat direksi, notulen rapat; mengatur, memonitor dan mengontrol seluruh telepon masuk untuk direksi; menyiapkan, melakukan kegiatan administrasi, mengatur, memonitor dan mengontrol seluruh kebutuhan surat menyurat yang efektif dan efisien; memegang rahasia penting pimpinan yang berkaitan dengan perusahaan.

Kualifikasi yang harus dipenuhi adalah pendidikan S1 semua jurusan, fresh graduate; pengalaman minimal satu tahun sebagai sekretaris direksi atau sekretaris perusahaan lebih diutamakan, penampilan menarik; pandai berkomunikasi dan cepat beradaptasi dengan lingkungan, bersedia bekerjasama dan siap bekerja keras, loyalitas dan terbiasa mandiri, menguasai microsoft office, bersedia melakukan perjalanan dinas. 
Tabel 6. Kebutuhan Kompetensi PT MGI

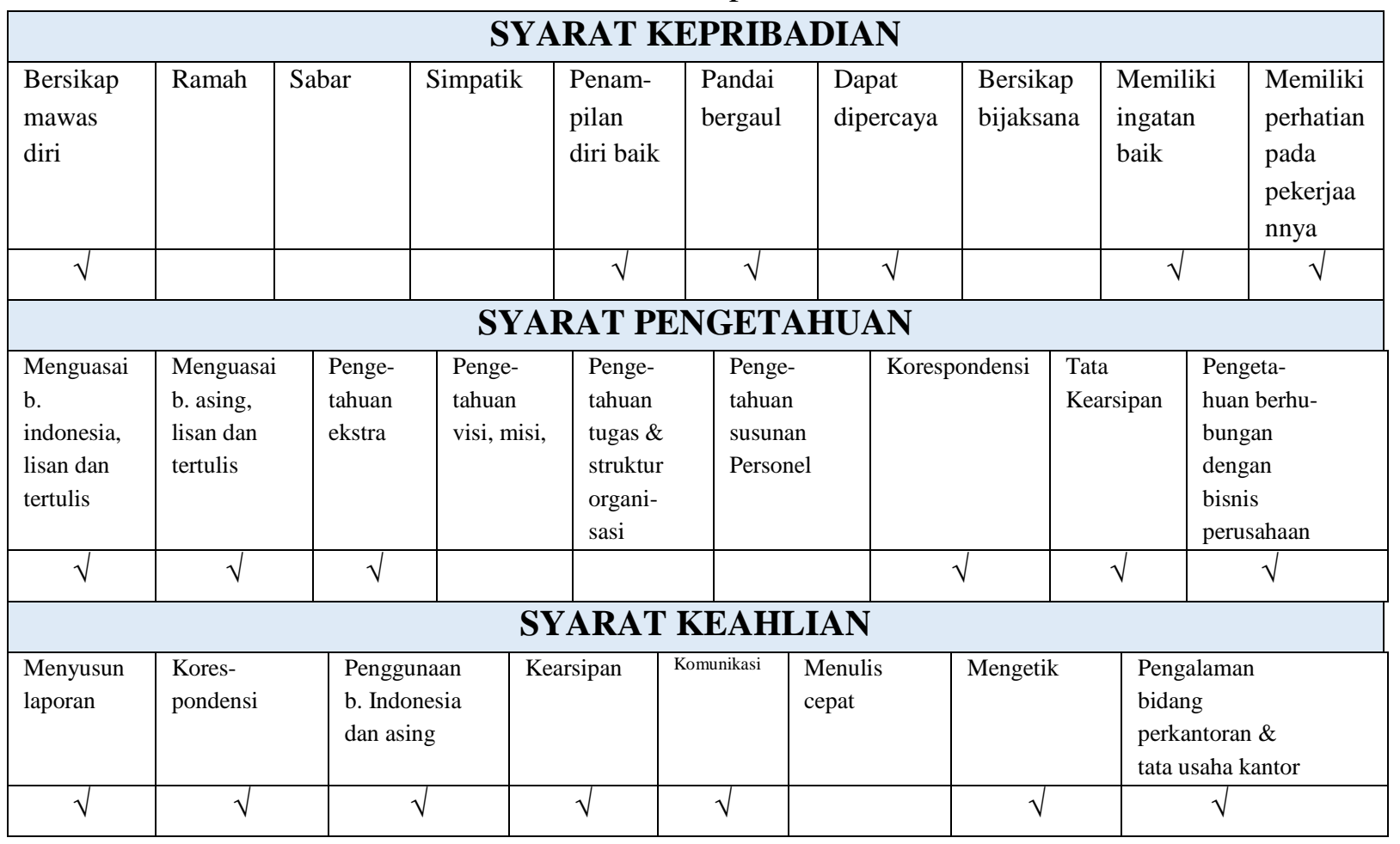

\section{Sekretaris Direksi, PT Angkasa Pura Retail (APR) - Jakarta}

PT Angkasa Pura Retail bergerak dibidang penjualan retail dan layanan pemasaran. Tugas dan tanggungjawab sekretaris direksi adalah menyusun agenda direktur; menyiapkan keperluan perjalanan/rapat/event; mengumpulkan data-data periodik setiap departemen untuk untuk dilaporkan ke direktur terkait, mengelola petty cash, mengelola klaim restitusi direktur, membuat notulen rapat setiap agenda meeting yang dijalankan direksi, menyelesaikan pekerjaan yang diinstruksikan, mengurus masalah administrasi direksi, mempersiapkan bahan-bahan rapat, mendampingi direksi pada saat rapat atau perjalanan dinas, melakukan kegiatan korespondensi direksi.

Kualifikasi yang harus dipenuhi adalah memiliki pendidikan diploma, gelar sarjana di bidang apapun, memiliki kemampuan berbahasa Indonesia dan Inggris aktif, memiliki pengalaman di bidang yang sesuai dengan posisi sekretaris direksi tiga tahun, menguasai microsoft office, lebih disukai supervisor/ koordinator khusus sekretaris, penampilan menarik dan komunikatif, terbiasa dengan deadline; multitasking; teliti dan responsif, dinamis; kreatif; komunikasi interpersonal; percaya diri; integritas tinggi. 
Tabel 7. Kebutuhan Kompetensi PT APR

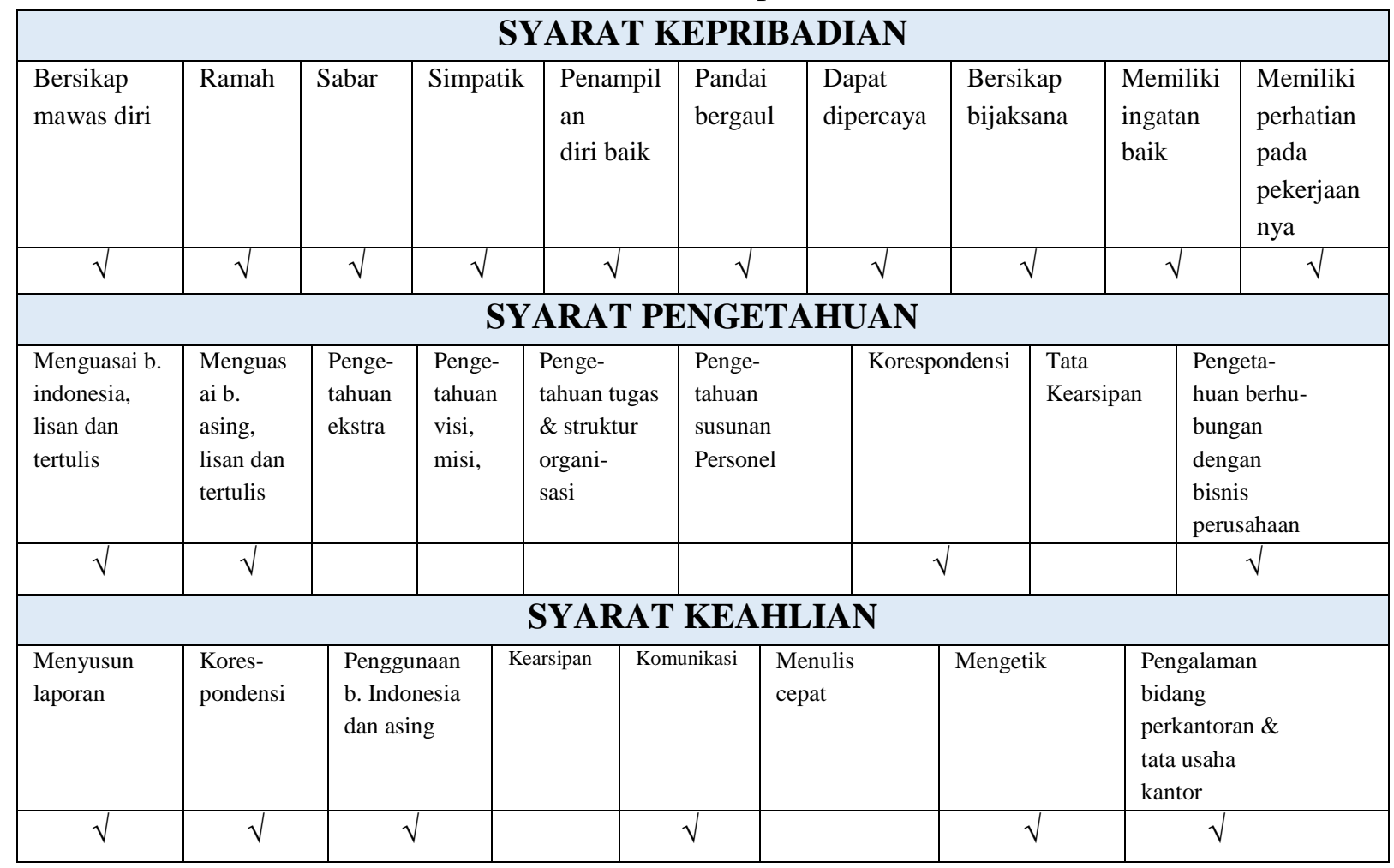

\section{Sekretaris Direksi, Gunawangsa Group (GG) - Surabaya.}

Gunawangsa Group adalah perusahaan pengembang properti, high rise building, residential, commercial, office dan hospitality. Tugas dan tanggungjawab sekretaris direksi adalah melakukan kegiatan kesekretariatan perusahaan, membantu kelancaran pelaksanaan agenda kegiatan direksi, memberikan masukan kepada direksi dari aspek hukum yang berkaitan dengan operasionalisasi dan pengembangan usaha perusahaan, bertanggungjawab dalam penyimpanan dokumen asli perusahaan, mengkomunikasi kebijakan perusahaan kepada pihak internal dan eksternal, mengkoordinasikan bahan-bahan laporan untuk rapat komisaris dan rapat umum pemegang saham, menyiapkan laporan keseluruhan tentang kegiatan sekretaris perusahaan secara benar dan tepat waktu.

Kualifikasi yang harus dipenuhi adalah pendidikan minimal S1 jurusan akuntansi, pengalaman minimal tiga tahun sebagai sekretaris direksi, disiplin; tanggungjawab; jujur; inisiatif; komunikatif dan memiliki ketrampilan presentasi, tegas dan berorientasi pada detail, penampilan menarik. 
Tabel 8. Kebutuhan Kompetensi PT GG

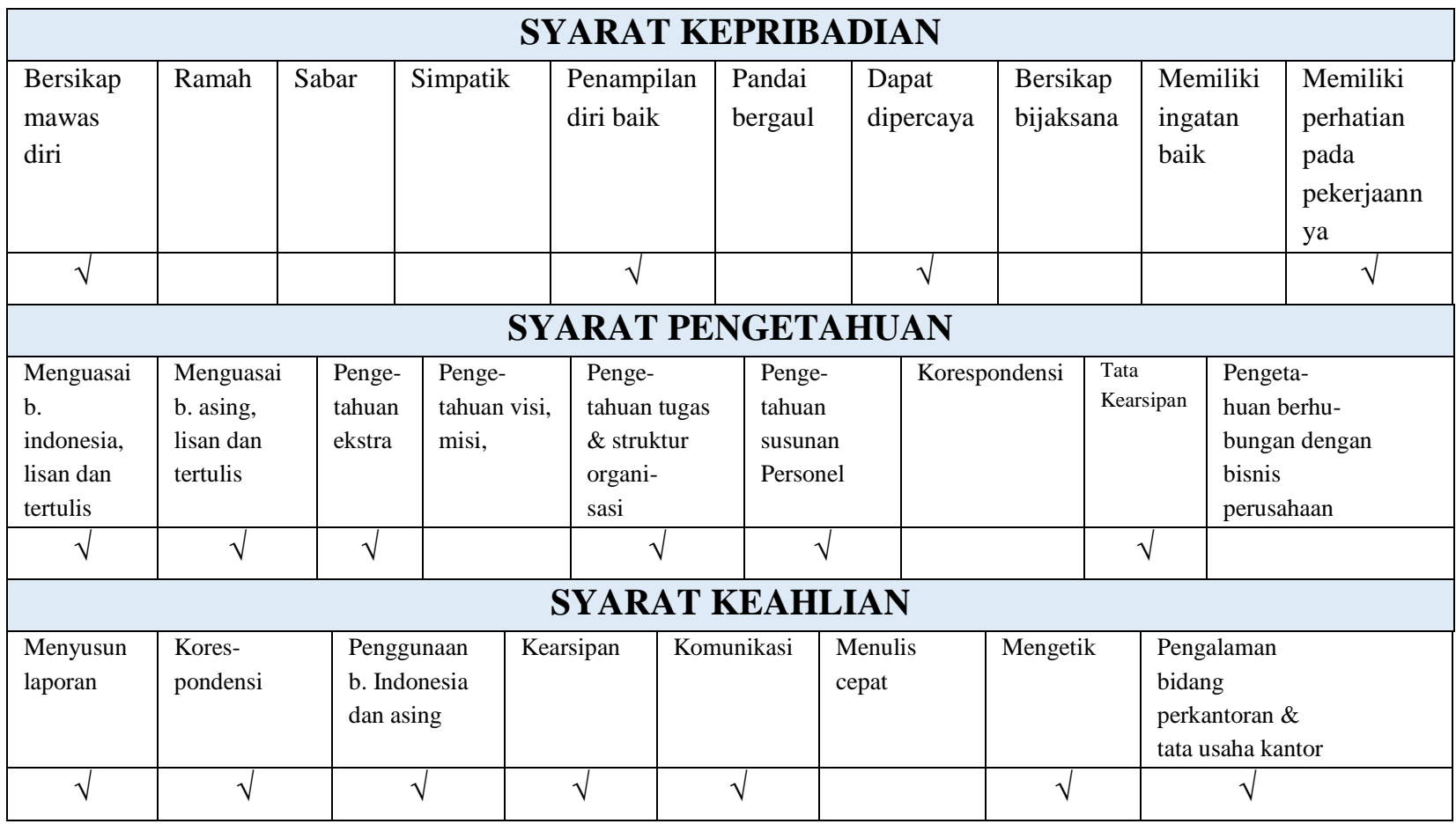

\section{Sekretaris Direksi, PT Priamanaya Energi (PE) - Jakarta}

PT Priamanaya Energi adalah perusahaan bergerak dibidang properti dan penambangan. Tugas dan tanggungjawab sekretaris direksi adalah mensupport pekerjaan atasan, menyusun laporan dan melakukan kegiatan pengarsipan, melakukan kegiatan korespondensi.Kualifikasi yang harus dipenuhi adalah lulusan S1 semua jurusan, memiliki kemampuan menyusun laporan; mengatur acara; mengarsip dokumen; korespondensi, memiliki kemampuan berbahasa Inggris verbal dan tertulis, komunikatif dan enerjik.

Tabel 9. Kebutuhan Kompetensi PT PE

\begin{tabular}{|c|c|c|c|c|c|c|c|c|c|c|c|c|c|c|}
\hline \multicolumn{15}{|c|}{ SYARAT KEPRIBADIAN } \\
\hline $\begin{array}{l}\text { Bersikap } \\
\text { mawas } \\
\text { diri }\end{array}$ & Ramah & \multirow[t]{2}{*}{ Sabar } & Simpati & & \multicolumn{2}{|c|}{$\begin{array}{l}\text { Penampilan } \\
\text { diri baik }\end{array}$} & $\begin{array}{l}\text { Pandai } \\
\text { bergaul }\end{array}$ & \multicolumn{2}{|c|}{$\begin{array}{l}\text { Dapat } \\
\text { dipercaya }\end{array}$} & $\begin{array}{l}\text { Bersika } \\
\text { bijaksar }\end{array}$ & & \multicolumn{2}{|c|}{$\begin{array}{l}\text { Memiliki } \\
\text { ingatan } \\
\text { baik }\end{array}$} & $\begin{array}{l}\text { Memiliki } \\
\text { perhatian } \\
\text { pada } \\
\text { pekerjaan } \\
\text { nya }\end{array}$ \\
\hline$\sqrt{ }$ & & & & & & & $\sqrt{ }$ & & $\sqrt{ }$ & & & \multicolumn{2}{|l|}{$\sqrt{ }$} & $\sqrt{ }$ \\
\hline \multicolumn{15}{|c|}{ SYARAT PENGETAHUAN } \\
\hline $\begin{array}{l}\text { Menguasai } \\
\text { b. } \\
\text { indonesia, } \\
\text { lisan dan } \\
\text { tertulis }\end{array}$ & \multirow{2}{*}{\multicolumn{2}{|c|}{$\begin{array}{l}\text { Menguasai } \\
\text { b. asing, } \\
\text { lisan dan } \\
\text { tertulis }\end{array}$}} & \multicolumn{2}{|c|}{$\begin{array}{l}\text { Penge- } \\
\text { tahuan } \\
\text { visi, misi, }\end{array}$} & \multicolumn{2}{|c|}{$\begin{array}{l}\text { Penge- } \\
\text { tahuan tugas } \\
\& \text { struktur } \\
\text { organi- } \\
\text { sasi }\end{array}$} & \multicolumn{2}{|c|}{$\begin{array}{l}\text { Penge- } \\
\text { tahuan } \\
\text { susunan } \\
\text { Personel }\end{array}$} & \multicolumn{2}{|c|}{ Korespondensi } & \multicolumn{2}{|c|}{$\begin{array}{l}\text { Tata } \\
\text { Kearsipan }\end{array}$} & \multicolumn{2}{|c|}{\begin{tabular}{|l|} 
Pengeta- \\
huan berhu- \\
bungan \\
dengan \\
bisnis \\
perusahaan \\
\end{tabular}} \\
\hline$\sqrt{ }$ & & & & & & & & & \multicolumn{2}{|c|}{$\sqrt{ }$} & & $\sqrt{ }$ & & $\sqrt{ }$ \\
\hline \multicolumn{15}{|c|}{ SYARAT KEAHLIAN } \\
\hline $\begin{array}{l}\text { Menyusun } \\
\text { laporan }\end{array}$ & $\begin{array}{l}\text { Kores- } \\
\text { pondensi }\end{array}$ & \multicolumn{2}{|c|}{$\begin{array}{l}\text { Penggunaan } \\
\text { b. Indonesia } \\
\text { dan asing }\end{array}$} & Kea & rsipan & \multicolumn{2}{|c|}{ Komunikasi } & $\begin{array}{l}\text { Menuli } \\
\text { cepat }\end{array}$ & & \multicolumn{2}{|c|}{ Mengetik } & \multicolumn{3}{|c|}{$\begin{array}{l}\text { Pengalaman } \\
\text { bidang } \\
\text { perkantoran \& } \\
\text { tata usaha kantor }\end{array}$} \\
\hline$\sqrt{ }$ & $\sqrt{ }$ & \multicolumn{2}{|c|}{$\sqrt{ }$} & & $\sqrt{ }$ & \multicolumn{2}{|r|}{$\sqrt{ }$} & & & \multicolumn{2}{|l|}{$\sqrt{ }$} & \multicolumn{3}{|c|}{$\sqrt{ }$} \\
\hline
\end{tabular}




\section{Sekretaris Direksi dan Korporasi, PT Satya Dharma Kardia (SDK) - Jakarta}

PT Satya Dharma Kardia adalah sebuah perusahaan yang memberikan pelayanan kesehatan jantung dengan membangun RS. Jantung Jakarta. Tugas dan tanggungjawab sekretaris direksi adalah melakukan kegiatan administrasi yang dapat menunjang pekerjaan dan kegiatan direksi yaitu korespondensi; review perjanjian; laporan unit kerja, mengorganisasikan kegiatan rutin direksi yaitu menjadwal rapat; perjalanan dinas dan aktifitas personal direksi, mencatat dan membuat minutes of meeting pada PIC terkait, menjadi perantara untuk tim internal dan eksternal yang akan berhubungan dengan direksi, mengarsip dokumen kegiatan administrasi bisnis dan personal direksi, menindaklanjuti surat direksi, menyortir surat direksi, mengkomunikasi permintaan surat/memo yang telah disetujui direksi kepada pihak internal dan eksternal.

Kualifikasi yang harus dipenuhi adalah pendidikan minimal D3/S1, menguasai bahasa Inggris lisan dan tertulis, memiliki pengalaman sebagai sekretaris direksi dan bidang terkait minimal tiga tahun, bersedia bekerja overtime; memiliki kemampuan time management; well organized; integritas tinggi; inisiatif tinggi; multitasking; wawasan luas, penampilan rapih dan enerjik, menguasai microsoft office dan diutamakan mampu menyiapkan laporan dan presentasi, memiliki kemampuan menyusun jadwal meeting untuk direksi, memiliki kemampuan komunikasi yang baik dengan semua level dan posisi.

Tabel 10. Kebutuhan Kompetensi PT SDK

\begin{tabular}{|c|c|c|c|c|c|c|c|c|c|c|c|c|c|c|}
\hline \multicolumn{15}{|c|}{ SYARAT KEPRIBADIAN } \\
\hline \multirow[t]{2}{*}{$\begin{array}{l}\text { Bersikap } \\
\text { mawas } \\
\text { diri }\end{array}$} & \multirow[t]{2}{*}{ Ramah } & \multirow[t]{2}{*}{ Sabar } & \multicolumn{2}{|c|}{ Simpatik } & \multicolumn{2}{|c|}{$\begin{array}{l}\text { Penampilan } \\
\text { diri baik }\end{array}$} & $\begin{array}{l}\text { Pandai } \\
\text { bergaul }\end{array}$ & \multicolumn{2}{|c|}{$\begin{array}{l}\text { Dapat } \\
\text { dipercaya }\end{array}$} & \multicolumn{2}{|c|}{$\begin{array}{l}\text { Bersikap } \\
\text { bijaksana }\end{array}$} & \multicolumn{2}{|c|}{$\begin{array}{l}\text { Memiliki } \\
\text { ingatan } \\
\text { baik }\end{array}$} & $\begin{array}{l}\text { Memiliki } \\
\text { perhatian } \\
\text { pada } \\
\text { pekerjaan } \\
\text { nya }\end{array}$ \\
\hline & & & & & \multicolumn{2}{|c|}{$\sqrt{ }$} & \multicolumn{3}{|l|}{$\sqrt{ }$} & \multicolumn{2}{|l|}{$\sqrt{ }$} & \multicolumn{2}{|c|}{$\sqrt{ }$} & $\sqrt{ }$ \\
\hline \multicolumn{15}{|c|}{ SYARAT PENGETAHUAN } \\
\hline $\begin{array}{l}\text { Menguasai } \\
\text { b. } \\
\text { indonesia, } \\
\text { lisan dan } \\
\text { tertulis }\end{array}$ & $\begin{array}{l}\text { Menguasai } \\
\text { b. asing, } \\
\text { lisan dan } \\
\text { tertulis }\end{array}$ & \multirow[t]{2}{*}{$\begin{array}{l}\text { Penge- } \\
\text { tahuan } \\
\text { ekstra }\end{array}$} & \multicolumn{2}{|c|}{$\begin{array}{l}\text { Penge- } \\
\text { tahuan } \\
\text { visi, misi, }\end{array}$} & \multicolumn{2}{|c|}{$\begin{array}{l}\text { Penge- } \\
\text { tahuan tugas } \\
\& \text { struktur } \\
\text { organi- } \\
\text { sasi }\end{array}$} & \multicolumn{2}{|c|}{$\begin{array}{l}\text { Penge- } \\
\text { tahuan } \\
\text { susunan } \\
\text { Personel }\end{array}$} & \multicolumn{2}{|c|}{ Korespondensi } & \multicolumn{2}{|c|}{$\begin{array}{l}\text { Tata } \\
\text { Kearsipan }\end{array}$} & \multicolumn{2}{|c|}{$\begin{array}{l}\text { Pengeta- } \\
\text { huan berhu- } \\
\text { bungan } \\
\text { dengan } \\
\text { bisnis } \\
\text { perusahaan }\end{array}$} \\
\hline$\sqrt{ }$ & $\sqrt{ }$ & & & & \multicolumn{2}{|c|}{$\sqrt{ }$} & \multicolumn{2}{|c|}{$\sqrt{ }$} & \multicolumn{2}{|c|}{$\sqrt{ }$} & \multicolumn{2}{|r|}{$\sqrt{ }$} & \multicolumn{2}{|r|}{$\sqrt{ }$} \\
\hline \multicolumn{15}{|c|}{ SYARAT KEAHLIAN } \\
\hline $\begin{array}{l}\text { Menyusun } \\
\text { laporan }\end{array}$ & $\begin{array}{l}\text { Kores- } \\
\text { pondensi }\end{array}$ & \multicolumn{2}{|c|}{$\begin{array}{l}\text { Penggunaan } \\
\text { b. Indonesia } \\
\text { dan asing }\end{array}$} & & sipan & \multicolumn{2}{|c|}{ Komunikasi } & $\begin{array}{l}\text { Menulis } \\
\text { cepat }\end{array}$ & & \multicolumn{2}{|c|}{ Mengetik } & \multicolumn{3}{|c|}{$\begin{array}{l}\text { Pengalaman } \\
\text { bidang } \\
\text { perkantoran \& } \\
\text { tata usaha kantor }\end{array}$} \\
\hline$\sqrt{ }$ & $\sqrt{ }$ & \multicolumn{2}{|r|}{$\sqrt{ }$} & & $\sqrt{ }$ & \multicolumn{2}{|r|}{$\sqrt{ }$} & & & $\sqrt{ }$ & & & $\sqrt{ }$ & \\
\hline
\end{tabular}


Tugas dan tanggungjawab sekretaris direksi adalah sebagai sumber informasi pimpinan, memfilter informasi yang masuk, menangani kegiatan administrasi kesekretariatan dan human relation, menjadi perantara antara pimpinan dengan bawahan, memberikan alternatif pemikiran kepada pimpinan, mampu memegang rahasia pimpinan, menyampaikan informasi mengenai kebijakan direksi kepada pihak eksternal dan internal, menyiapkan laporan, menyusun agenda kegiatan direksi, menjadi notula dan membuat notulen rapat, mengelola dokumen, mengorganisasikan pertemuan bisnis, mampu bersikap tegas dan cepat dalam mengambil keputusan, mengelola data base, membuat kontrak dan surat perjanjian, menangani dokumen bank dan dokumen penting lainnya, menyiapkan dokumen yang diperlukan dengan benar dan tepat waktu, menangani surat menyurat direksi, menangani perjalanan dinas direksi, mengumpulkan data periodik dari departemen terkait untuk dilaporkan ke direktur, mengelola petty cash dan klaim restitusi direktur, mengoordinasikan bahan-bahan laporan untuk keperluan rapat komisaris dan rapat umum pemegang saham.

Tugas dan tanggung jawab tersebut dapat dilaksanakan dengan profesional, apabila sekretaris direksi memiliki kompetensi sebagai berikut :

1. Syarat kepribadian seorang sekretaris.

Tabel 11. Syarat Kepribadian Seorang Sekretaris

\begin{tabular}{|c|c|c|c|c|c|c|c|c|c|c|}
\hline $\begin{array}{l}\text { Peru- } \\
\text { sahaan }\end{array}$ & $\begin{array}{c}\text { Bersikap } \\
\text { mawas } \\
\text { diri }\end{array}$ & $\begin{array}{l}\mathrm{Ra}- \\
\mathrm{mah}\end{array}$ & $\begin{array}{l}\text { Sa- } \\
\text { bar }\end{array}$ & $\begin{array}{l}\text { Sim- } \\
\text { patik }\end{array}$ & $\begin{array}{c}\text { Penam- } \\
\text { pilan } \\
\text { diri baik }\end{array}$ & $\begin{array}{l}\text { Pandai } \\
\text { bergaul }\end{array}$ & $\begin{array}{c}\text { Dapat diper- } \\
\text { caya }\end{array}$ & $\begin{array}{l}\text { Bersikap } \\
\text { bijaksana }\end{array}$ & $\begin{array}{l}\text { Memili ki } \\
\text { ingatan } \\
\text { baik }\end{array}$ & $\begin{array}{c}\text { Memiliki } \\
\text { perhatian } \\
\text { pada } \\
\text { pekerjaan } \\
\text { nya }\end{array}$ \\
\hline PT SSJ & & $\sqrt{ }$ & & $\sqrt{ }$ & $\sqrt{ }$ & $\sqrt{ }$ & $\sqrt{ }$ & $\sqrt{ }$ & $\sqrt{ }$ & $\sqrt{ }$ \\
\hline PT WKK & $\sqrt{ }$ & & & & $\sqrt{ }$ & $\sqrt{ }$ & $\sqrt{ }$ & $\sqrt{ }$ & $\sqrt{ }$ & $\sqrt{ }$ \\
\hline PT KRU & $\sqrt{ }$ & & & & & & $\sqrt{ }$ & $\sqrt{ }$ & $\sqrt{ }$ & $\sqrt{ }$ \\
\hline PT KSI & $\sqrt{ }$ & $\sqrt{ }$ & $\sqrt{ }$ & $\sqrt{ }$ & & $\sqrt{ }$ & $\sqrt{ }$ & $\sqrt{ }$ & $\sqrt{ }$ & $\sqrt{ }$ \\
\hline PT ISN & $\sqrt{ }$ & & & & & & $\sqrt{ }$ & $\sqrt{ }$ & $\sqrt{ }$ & $\sqrt{ }$ \\
\hline PT MGI & $\sqrt{ }$ & & & & $\sqrt{ }$ & $\sqrt{ }$ & $\sqrt{ }$ & & $\sqrt{ }$ & $\sqrt{ }$ \\
\hline PT APR & $\sqrt{ }$ & $\sqrt{ }$ & $\sqrt{ }$ & $\sqrt{ }$ & $\sqrt{ }$ & $\sqrt{ }$ & $\sqrt{ }$ & $\sqrt{ }$ & $\sqrt{ }$ & $\sqrt{ }$ \\
\hline PT GG & $\sqrt{ }$ & & & & $\sqrt{ }$ & & $\sqrt{ }$ & & & $\sqrt{ }$ \\
\hline PT PE & $\sqrt{ }$ & & & & & $\sqrt{ }$ & $\sqrt{ }$ & & $\sqrt{ }$ & $\sqrt{ }$ \\
\hline PT SDK & & & & & $\sqrt{ }$ & $\sqrt{ }$ & $\sqrt{ }$ & $\sqrt{ }$ & $\sqrt{ }$ & $\sqrt{ }$ \\
\hline Total & 8 & 3 & 3 & 3 & 6 & 7 & 10 & 7 & 9 & 10 \\
\hline
\end{tabular}

Kepribadian yang kuat pada seorang sekretaris direksi dicirikan oleh perilaku tampaknya (overt) yang menaruh perhatian tinggi pada pekerjaannya, dapat dipercaya, memiliki ingatan yang baik, dapat bersikap mawas diri, cukup luwes dalam bergaul, berpenampilan profesional. Utamanya seorang sekretaris direksi harus memiliki rasa tanggung jawab yang tinggi. Sementara sikap seperti ramah, sabar dan simpatik hanya diperlukan pada indutri tertentu saja. 
2. Syarat Pengetahuan

Tabel 12. Syarat Pengetahuan Seorang Sekretaris

\begin{tabular}{|c|c|c|c|c|c|c|c|c|c|}
\hline $\begin{array}{l}\text { Peru- } \\
\text { sahaan }\end{array}$ & $\begin{array}{l}\text { Menguasai } \\
\text { b. indone- } \\
\text { sia, lisan } \\
\text { dan tertulis }\end{array}$ & $\begin{array}{l}\text { Mengu- } \\
\text { asai b. } \\
\text { asing, } \\
\text { lisan dan } \\
\text { tertulis }\end{array}$ & $\begin{array}{l}\text { Penge- } \\
\text { tahuan } \\
\text { ekstra }\end{array}$ & $\begin{array}{l}\text { Pengeta } \\
\text { huan } \\
\text { visi, } \\
\text { misi, }\end{array}$ & $\begin{array}{l}\text { Penge- } \\
\text { tahuan } \\
\text { tugas \& } \\
\text { struktur } \\
\text { organi- } \\
\text { sasi }\end{array}$ & $\begin{array}{c}\text { Penge- } \\
\text { tahuan } \\
\text { susu- } \\
\text { nan } \\
\text { Perso- } \\
\text { nel }\end{array}$ & $\begin{array}{l}\text { Kores- } \\
\text { ponden- } \\
\text { si }\end{array}$ & $\begin{array}{l}\text { Tata } \\
\text { Kear- } \\
\text { sipan }\end{array}$ & $\begin{array}{l}\text { Pengeta- } \\
\text { huan } \\
\text { berhu- } \\
\text { bungan } \\
\text { dengan } \\
\text { bisnis } \\
\text { perusahaan }\end{array}$ \\
\hline PT SSJ & $\sqrt{ }$ & $\sqrt{ }$ & $\sqrt{ }$ & & $\sqrt{ }$ & $\sqrt{ }$ & & & $\sqrt{ }$ \\
\hline PT WKK & $\sqrt{ }$ & $\sqrt{ }$ & $\sqrt{ }$ & $\sqrt{ }$ & $\sqrt{ }$ & $\sqrt{ }$ & $\sqrt{ }$ & & $\sqrt{ }$ \\
\hline PT KRU & $\sqrt{ }$ & $\sqrt{ }$ & & & $\sqrt{ }$ & $\sqrt{ }$ & $\sqrt{ }$ & $\sqrt{ }$ & $\sqrt{ }$ \\
\hline PT KSI & & $\sqrt{ }$ & $\sqrt{ }$ & & & & $\sqrt{ }$ & & $\sqrt{ }$ \\
\hline PT ISN & $\sqrt{ }$ & $\sqrt{ }$ & $\sqrt{ }$ & & $\sqrt{ }$ & $\sqrt{ }$ & $\sqrt{ }$ & $\sqrt{ }$ & $\sqrt{ }$ \\
\hline PT MGI & $\sqrt{ }$ & $\sqrt{ }$ & $\sqrt{ }$ & & & & $\sqrt{ }$ & $\sqrt{ }$ & $\sqrt{ }$ \\
\hline PT APR & $\sqrt{ }$ & $\sqrt{ }$ & & & & & $\sqrt{ }$ & & $\sqrt{ }$ \\
\hline PT GG & $\sqrt{ }$ & $\sqrt{ }$ & $\sqrt{ }$ & & $\sqrt{ }$ & $\sqrt{ }$ & & $\sqrt{ }$ & \\
\hline PT PE & $\sqrt{ }$ & $\sqrt{ }$ & & & & & $\sqrt{ }$ & $\sqrt{ }$ & $\sqrt{ }$ \\
\hline PT SDK & $\sqrt{ }$ & $\sqrt{ }$ & & & $\sqrt{ }$ & $\sqrt{ }$ & $\sqrt{ }$ & $\sqrt{ }$ & $\sqrt{ }$ \\
\hline Total & 8 & 10 & 6 & 1 & 6 & 6 & 8 & 6 & 9 \\
\hline
\end{tabular}

Memiliki kompetensi pengetahuan dalam penguasaan bahasa asing lisan dan tertulis, penguasaan terhadap bisnis perusahaan yang didukung dengan kemampuan dalam melakukan korespondensi dan penguasaan bahasa Indonesia lisan dan tertulis maupun keterampilan dalam kearsipan, pengetahuan tentang tugas dan struktur organisasi, serta susunan personel merupakan kompetensi-kompetensi yang menjadi kebutuhan seorang sekretaris direksi pada semua bidang industri yang diteliti.

3. Syarat Keahlian

Tabel 13. Syarat Keahlian Seorang Sekretaris

\begin{tabular}{|c|c|c|c|c|c|c|c|c|}
\hline $\begin{array}{l}\text { Peru- } \\
\text { sahaan }\end{array}$ & $\begin{array}{l}\text { Menyu- } \\
\text { sun } \\
\text { laporan }\end{array}$ & $\begin{array}{l}\text { Korespon- } \\
\text { densi }\end{array}$ & $\begin{array}{l}\text { Penggunaan } \\
\text { b. Indonesia } \\
\text { dan asing }\end{array}$ & $\begin{array}{l}\text { Kear- } \\
\text { sipan }\end{array}$ & $\begin{array}{c}\text { Komunika } \\
- \text {-si }\end{array}$ & $\begin{array}{c}\text { Menulis } \\
\text { cepat }\end{array}$ & Mengetik & $\begin{array}{c}\text { Pengalaman } \\
\text { bidang } \\
\text { perkantoran \& } \\
\text { tata usaha } \\
\text { kantor }\end{array}$ \\
\hline PT SSJ & & & $\sqrt{ }$ & & $\sqrt{ }$ & & & $\sqrt{ }$ \\
\hline PT WKK & $\sqrt{ }$ & $\sqrt{ }$ & $\sqrt{ }$ & & $\sqrt{ }$ & & $\sqrt{ }$ & $\sqrt{ }$ \\
\hline PT KRU & $\sqrt{ }$ & $\sqrt{ }$ & $\sqrt{ }$ & $\sqrt{ }$ & $\sqrt{ }$ & & $\sqrt{ }$ & $\sqrt{ }$ \\
\hline PT KSI & & $\sqrt{ }$ & $\sqrt{ }$ & & $\sqrt{ }$ & & $\sqrt{ }$ & $\sqrt{ }$ \\
\hline PT ISN & $\sqrt{ }$ & $\sqrt{ }$ & $\sqrt{ }$ & $\sqrt{ }$ & $\sqrt{ }$ & & $\sqrt{ }$ & $\sqrt{ }$ \\
\hline PT MGI & $\sqrt{ }$ & $\sqrt{ }$ & $\sqrt{ }$ & $\sqrt{ }$ & $\sqrt{ }$ & & $\sqrt{ }$ & $\sqrt{ }$ \\
\hline PT APR & $\sqrt{ }$ & $\sqrt{ }$ & $\sqrt{ }$ & & $\sqrt{ }$ & & $\sqrt{ }$ & $\sqrt{ }$ \\
\hline PT GG & $\sqrt{ }$ & $\sqrt{ }$ & $\sqrt{ }$ & $\sqrt{ }$ & $\sqrt{ }$ & & $\sqrt{ }$ & $\sqrt{ }$ \\
\hline PT PE & $\sqrt{ }$ & $\sqrt{ }$ & $\sqrt{ }$ & $\sqrt{ }$ & $\sqrt{ }$ & & $\sqrt{ }$ & $\sqrt{ }$ \\
\hline PT SDK & $\sqrt{ }$ & $\sqrt{ }$ & $\sqrt{ }$ & $\sqrt{ }$ & $\sqrt{ }$ & & $\sqrt{ }$ & $\sqrt{ }$ \\
\hline Total & 8 & 9 & 10 & 6 & 10 & & 9 & 10 \\
\hline
\end{tabular}


Keahlian dalam berkomunikasi, penggunaan bahasa Indonesia dan asing, korespondensi, penyusunan laporan dan pengarsipan merupakan kompetensi-kompetensi yang harus dikuasai oleh seorang sekretaris direksi. Tidak cukup hanya itu, pada penelitian ini syarat keahlian lain yang menjadi cukup krusial adalah dimilikinya pengalaman dalam menangani pekerjaan di bidang perkantoran dan tata usaha kantor.

\section{KESIMPULAN}

Berdasarkan hasil penelitian sekunder diatas, maka persyaratan utama yang harus dimiliki oleh sekretaris direksi agar kompeten dalam menjalankan tugas adalah memiliki kepribadian, pengetahuan dan keahlian yang memenuhi standar kualifikasi yang tinggi.

Dari sisi kepribadian, sepuluh perusahaan yang menjadi objek penelitian mensyaratkan sekretaris direksi merupakan seseorang yang dapat dipercaya dan memiliki perhatian pada pekerjaannya. Sembilan perusahaan mensyaratkan agar sekretarisnya memiliki ingatan yang baik. Delapan perusahaan mensyaratkan sekretarisnya memiliki sikap mawas diri. Tujuh perusahaan mensyaratkan sekretarisnya mampu bersikap bijaksana. Tiga perusahaan menginginkan sekretaris mereka memiliki kepribadian yang ramah, sabar dan simpatik. Kompetensi tersebut dibutuhkan untuk menyelesaikan tugas dan tanggungjawab sebagai sumber informasi bagi pimpinan, memfilter informasi yang masuk, menjadi perantara antara pimpinan dengan bawahan, mampu memegang rahasia pimpinan, mampu bersikap tegas dan cepat dalam mengambil keputusan.

Dari sisi pengetahuan, sepuluh perusahaan mensyaratkan sekretarisnya menguasai bahasa asing, lisan dan tertulis. Sembilan perusahaan mensyaratkan sekretaris direksi yang memiliki pengetahuan yang berhubungan dengan bisnis perusahaan. Delapan perusahaan mensyaratkan sekretaris direksi yang menguasai bahasa Indonesia lisan dan tertulis, memiliki pengetahuan tentang korespondensi, enam perusahaan menginginkan sekretaris direksi yang memiliki pengetahuan esktra, pengetahuan tentang tugas dan struktur organisasi dan pengetahuan tentang susunan personel. Satu perusahaan membutuhkan sekretaris yang memiliki pengetahuan tentang visi dan misi perusahaan. Kompetensi tersebut dibutuhkan untuk menyelesaikan tugas dan tanggungjawab menyampaikan informasi mengenai kebijakan direksi kepada pihak eksternal dan internal, membuat kontrak dan surat perjanjian, memberikan alternatif pemikiran kepada pimpinan, menangani dokumen bank dan dokumen penting lainnya, mengorganisasikan pertemuan bisnis, menyiapkan dokumen yang diperlukan dengan benar dan tepat waktu, menangani surat menyurat direksi, menangani perjalanan dinas direksi, mengelola petty cash dan klaim restitusi direktur, mengoordinasikan bahan-bahan laporan untuk keperluan rapat komisaris dan rapat umum pemegang saham. 
Untuk sisi keahlian, sepuluh perusahaan menginginkan sekretaris direksi yang memiliki keahlian menggunakan bahasa Indonesia dan asing, memiliki ketrampilan berkomunikasi dan memiliki pengalaman bidang perkantoran dan tata usaha kantor. Sembilan perusahaan mensyaratkan sekretarisnya memiliki kompetensi dalam mengetik dan korespondensi. Delapan perusahaan membutuhkan sekretaris direksi dengan keahlian menyusun laporan. Enam perusahaan membutuhkan sekretaris direksi yang memiliki keahlian mengarsip. Kompetensi tersebut dibutuhkan untuk menyelesaikan tugas dan tanggungjawab sumber informasi pimpinan, menangani kegiatan administrasi kesekretariatan dan human relation, menjadi perantara antara pimpinan dengan bawahan, menyampaikan informasi mengenai kebijakan direksi kepada pihak eksternal dan internal, menyiapkan laporan, menyusun agenda kegiatan direksi, menjadi notula dan membuat notulen rapat, mengelola dokumen, mengelola data base, membuat kontrak dan surat perjanjian, menangani dokumen bank dan dokumen penting lainnya, menyiapkan dokumen yang diperlukan dengan benar dan tepat waktu, menangani surat menyurat direksi, mengoordinasikan bahan-bahan laporan untuk keperluan rapat komisaris dan rapat umum pemegang saham.

Implikasinya, penelitian ini dapat dimanfaatkan oleh individu yang berminat menjadi sekretaris direksi dalam melakukan pengembangan diri agar dapat memenuhi kualifikasi sesuai dengan kompetensi minimal yang harus dipenuhi. Disarankan agar perusahaan yang membutuhkan sekretaris direksi dapat memberikan informasi lengkap dan detail mengenai tugas dan tanggungjawab yang akan dilaksanakan, sehingga calon sekretaris direksi mampu mengukur diri dan mempersiapkan diri dengan kompetensi yang dibutuhkan yang memenuhi prinsip the right secretary in the right place.

\section{DAFTAR PUSTAKA}

Gaol CJL. 2015. Keandalan dan Sukses Sekretaris Perusahaan dan Organisasi. Jakarta: PT Elex Media Komputindo.

Selfiana. 2018. Kompetensi Sekretaris Terkini Menghadapi Era Revolusi Industri 4.0 Di Sepuluh BUMN Indonesia. Jurnal Administrasi Kantor, 6 920, 163-172.

Wibowo. 2010. Budaya Organisasi. Jakarta: PT Rajagrafindo Persada.

Widiawati K, Selfiana. 2018. Kompetensi dan kebutuhan sekretaris dan administrasi profesional terkini di sepuluh perusahaan indonesia. Ikraith-Humaniora, 2 (2), 24-30, diambil dari http://journals.upi-yai.ac.id/index.php/ikraith-humaniora/article/view/221/120 


\section{UCAPAN TERIMA KASIH}

Penulis mengucapkan terima kasih kepada rekan-rekan dosen yang telah memberikan masukan sehingga penelitian ini dapat diselesaikan. Terima kasih juga disampaikan kepada pihak redaksi yang telah bersedia menerima hasi penelitian ini.

\section{PROFIL PENULIS}

Selfiana adalah penulis dan dosen di Akademi Sekretari dan Manajemen Bina Insani. Penelitiannya berfokus pada kompetensi sekretaris dan komunikasi. Hasil penelitian seputar kompetensi sekretaris berjudul kompetensi dan kebutuhan sekretaris dan administrasi profesional terkini di sepuluh perusahaan Indonesia, kompetensi sekretaris terkini menghadapi era revolusi Industri 4.0. di sepuluh BUMN Indonesia. Saat ini penulis sedang melakukan penelitian berjudul mengelola sekretaris dengan kompetensi sesuai kebutuhan masa depan melalui strength based talent management dan merupakan penerima hibah penelitian dosen pemula tahun 2019 . 